\title{
TRABALHO E NATUREZA NAS REPRESENTAÇÕES SOCIAIS DOS CONTOS E CAUSOS ${ }^{1}$
}

\author{
Marivaldo Aparecido de Carvalho ${ }^{2}$ \\ Rosana Passos Cambraia ${ }^{3}$ \\ Silvia Regina Paes ${ }^{4}$
}

\begin{abstract}
RESUMO
Atentamos para as representações sociais expressas pelos contos e causos e pela maneira como as comunidades rurais percebem a natureza envolvente. $O$ trabalho objetivou valorar as relações culturais e a memória coletiva, com participação de narradores e historiadores. Foram realizadas gravações, coletas e sistematização dos relatos e narrações em algumas comunidades rurais tradicionais do Vale do Jequitinhonha e do Sul de Minas Gerais (Brasil). As ações tiveram como foco a produção de texto e a publicação de livros e cartilhas. Os contos se apresentam estruturados pelas formas do trabalho, a natureza é vista como criação de Deus e espaço fundamental para o ato do trabalho. Seja na relação entre os moradores e as unidades de conservação da natureza, ou monocultivos, o homem rural se relaciona com outras formas de organização do trabalho e com a percepção da natureza. $O$ 'trabalho' se coloca como elemento aglutinante entre a organização da economia camponesa e a percepção da natureza. A manifestação social dessa aglutinação se dá nas narrativas dos contos, de forma imaginária, as lidas da vida diária, demonstram os aspectos éticos/religiosos dos valores sociais que norteiam hábitos, costumes e manifestações culturais.
\end{abstract}

Palavras-chave: antropologia rural, cultura, estórias, religiosidade.

\section{NATURE AND LABOR IN SOCIAL REPRESENTATION OF TALES AND STORIES}

\begin{abstract}
We look at the social representations that are expressed by tales and stories and the way that rural communities perceive the surrounding nature. The goals of this work were to strengthen cultural ties and to value collective memory, with the participation of narrators and historians of the rural communities. We recorded, collected and
\end{abstract}

\footnotetext{
${ }^{1}$ Fomento da Fundação de Amparo à Pesquisa do Estado de Minas Gerais (FAPEMIG), APQ 002797-14. 2 Graduado em Ciências Sociais (UNESP). Mestrado e Doutorado em Sociologia (UNESP). Professor dos Programas de Pós-Graduação em Saúde, Sociedade e Ambiente (PPGSaSA) e Estudos Rurais (PPGER) da Universidade Federal dos Vales do Jequitinhonha e Mucuri (UFVJM). Email: marivaldo.aparecido@ufvjm.edu.br

${ }^{3}$ Graduada em Zootecnia (UFV). Mestrado e Doutorado em Psicobiologia (USP). Professora dos Programas de Pós-Graduação em Saúde, Sociedade e Ambiente (PPGSaSA) e Estudos Rurais (PPGER) da Universidade Federal dos Vales do Jequitinhonha e Mucuri (UFVJM). E-mail: rosa.cambraia@ufvjm.edu.br ${ }^{4}$ Graduada em Ciências Sociais (UNESP). Mestrado e Doutorado em Sociologia (UNESP). Professora do Programa de Pós-Graduação em Saúde, Sociedade e Ambiente (PPGSaSA) da Universidade Federal dos Vales do Jequitinhonha e Mucuri (UFVJM).E-mail: silvia.paes@ufvjm.edu.br
} 
systematized the reports and narrations in some traditional communities of the Jequitinhonha Valley and South Minas Gerais (Brazil), to publication of the stories and narrations as articles, books and booklets. The work structure in the stories and nature is seen as a creation of God, a fundamental space for the work. Whether in the relationship between communities and units of nature conservation, or monocultures, the rural people are related to other forms of work organization and the perception of nature. The 'work' is placed as an agglutinative element between the organization of the peasant economy and their perception of nature. The social manifestation of this agglutination occurs in the ways of narrating the stories, in an imaginary way, the daily life, demonstrated by the ethical and religious aspects of social values guiding habits, customs and cultural manifestations.

Key words: rural anthropology, culture, stories, religiosity.

\section{INTRODUÇÃO}

As narrações de contos e causos demonstram que a memória é sempre coletiva, ou seja, mesmo a memória individual é referendada pela sociabilidade dada pela coletividade onde este indivíduo habita. O imaginário social, expresso em contos e narrações, possibilita uma observação mais complexa do real social vivido, assim o imaginário se relaciona com a memória.

Como um fenômeno social a memória se constrói, segundo Halbwachs (2006), dentro do social; nos indica, também, que 'necessita' de noções de tempo e de espaço, como elementos fundamentais para o avivamento da mesma, pois as localizações espaciais e temporais das lembranças se mostram como elementos essenciais da memória. Assim, quando tentamos refletir sobre o imaginário de uma população com referência ao seu espaço ambiental, estaremos ao mesmo tempo trabalhando com elementos similares aos da memória. Pois a ação do grupo social determina a reconstrução das lembranças, tornando assim a memória um fenômeno social (BARROS, 1989). Os contos apresentam substratos didáticos, aprendizados estéticos e morais, pois representam, de forma literária, condutas que as pessoas deveriam ter ou respeitar para a melhor relação com o mundo social e natural envolvente, assim como entre as pessoas, no seu cotidiano. São 'recados' sociais validados pelos mais velhos, pela experiência da vida. Assim os contos são didáticos por expressarem sentidos éticos, econômicos, religiosos e comportamentais. O conto revela uma leitura humana do mundo envolvente natureza/social.

O homem intervém na confusão do universo; aprofunda, reduz, congrega; reúne os elementos conexos, separa, divide, decompõe e repõe o essencial em pequenas pilhas. As diferenças ampliam-se, o equívoco é eliminado ou então devolvido à univocidade. Pelo desenvolvimento da explicação e o cercamento da classificação, chega-se, pois às formas fundamentais. (JOLLES, 1976, p.29)

Segundo este mesmo autor o conto se congrega às formas simples, que poderíamos denominar como uma forma fundamental (no sentido acima colocado), como uma experiência humana de ordenamento do mundo que se processa através da linguagem; a linguagem como processo de ordenação do mundo dado e vivido.

Em primeiro lugar, a linguagem atribui um nome a tudo o que foi cultivado, fabricado, interpretado. Depois - e mais 
profundamente -, a própria linguagem é um princípio de cultura, de fabricação e de interpretação, na qual se produz, com a maior especificidade, a vinculação a uma determinada ordem. (JOLLES, 1976, p.25)

Neste sentido apresentamos uma leitura teórica do conto, com a intenção de pensar o conto como um elemento que revela uma leitura humana do mundo envolvente (natureza), como também do mundo social. O objetivo deste trabalho foi valorar as relações culturais da comunidade, a memória coletiva, com participação de narradores e historiadores de algumas comunidades rurais.

\subsection{PROCEDIMENTOS METODOLÓGICOS}

As ações tiveram como foco a produção textual e a publicação em livros e cartilhas. Participaram moradores dos distritos rurais de Padre João Afonso (Itamarandiba) e São Gonçalo do Rio das Pedras (Serro) na porção alta do Vale do Jequitinhonha, e no Sul de Minas do Bairro da Pedra (Aiuruoca). Foram realizadas gravações, coletas e sistematização dos relatos e narrações nestas comunidades em Minas Gerais. As atividades foram norteadas na auto valoração cultural das comunidades e no fomento pelo interesse na leitura.

No planejamento da atividade de extensão em interface com pesquisa, partimos da memória coletiva do grupo, representada por indivíduos que são considerados como mestres locais, como a 'memória viva' da comunidade. O procedimento para as entrevistas e coletas de informações respeitou hábitos e costumes locais. As pessoas entrevistadas foram indicadas localmente e decidiram sobre o melhor momento e o local para as conversas. As entrevistas foram gravadas em gravadores digitais e/ou anotadas em cadernos de campo, também foram realizadas filmagens e fotografias. O trabalho atendeu a resolução n. 466/2012 do Conselho Nacional de Saúde (BRASIL, 2012) e recebeu parecer favorável do Comitê de Ética em Pesquisa (CEP/UFVJM) para sua realização.

São Gonçalo do Rio das Pedras é um distrito do município do Serro (MG) dista $39 \mathrm{~km}$ da cidade de Diamantina e $27 \mathrm{~km}$ da cidade do Serro. Localiza-se no alto Vale do Jequitinhonha; os dados históricos indicam que sua fundação ocorreu em 1729; hoje São Gonçalo do Rio das Pedras busca desenvolver uma economia baseada no turismo (o distrito faz parte do circuito da Estrada Real).

O distrito de Padre João Afonso está situado a $42 \mathrm{~km}$ da sede municipal Itamarandiba (MG). Muitas são as belezas naturais, destacando-se o Parque Estadual da Serra Negra, um dos principais atrativos naturais do município. Os seus moradores se utilizam de paisagens naturais para desenvolverem seus plantios, como por exemplo a vazante do Rio Itamarandiba do Mato, que passa pela comunidade.

A comunidade Bairro da Pedra encontra-se a $11 \mathrm{~km}$ de Aiuruoca ('Casa de Papagaio' em Tupi-Guarani), um município encravado nas montanhas do Sul de Minas Gerais, próximo a Caxambu, Baependi e São Tomé das Letras. É um município onde se destaca o famoso Pico do Papagaio, que contribuiu para os nomes da cidade e de seu rio principal.

\subsection{SOBRE LUGARES, TERRA E NATUREZA}

Aiuruoca foi fundada em 1706, fechando o ciclo das primeiras bandeiras que partiam de São Paulo (VASCONCELOS, 1974, p.188). Já na época de sua 
fundação, o Pico do Papagaio se destacava como ponto de referência geográfico e social:

Aiuruoca, vocábulo de língua brasílica, quer dizer no nosso idioma: Casa de Papagaios, aludindo a um penhasco redondo e elevado aos ares, sobre um dos mais altos montes daquele lugar, em que os papagaios faziam sua morada, naquele tempo em que os gentios habitavam aqueles lugares... (TAUNAY, 1981, p.47)

Assim, o topônimo em si já representa uma leitura humana do espaço, onde a observação empírica se destaca. A região de Aiuruoca é rica em topônimos, muitos oriundos da ação de bandeirantes, outros possivelmente de uma presença indígena no local.

A maioria da população vive nas áreas rurais, onde pratica a agricultura de auto consumo (milho, feijão, batatinha, bananas, etc.); a atividade agropecuária se resume na criação de gado para venda do leite, fonte quase única de dinheiro, que hoje decaiu muito devido a presença do parque do Pico do Papagaio, e a proibição do uso comunitário secular que as comunidades rurais faziam dos campos de altitudes para a alimentação do gado. Com a proibição, a produção de leite teve uma queda drástica levando a população a trabalhar nas várias pousadas que foram abertas nos últimos anos. Alguns moradores conseguiram a aposentadoria. Atualmente encontramos nas áreas rurais pequenas fábricas de queijo, que é vendido para fora. A produção de queijos se dá de forma artesanal, cada morador fazendo o seu para consumo próprio e venda de excedente; produção também afetada pela presença do parque e de normas sanitárias rígidas.

No final da década de 1970 e início de 1980, a região passou a receber muitas pessoas vindas de centros urbanos, atraídas pela beleza natural do local. Tal atração não se deu somente por uma leitura estritamente ecológica, mas também por uma ótica religiosa, esotérica.

Há um forte impacto quando as famílias são proibidas de se apropriarem de 'recursos naturais' pela prática da coleta ou mesmo caça ou extrativismo, porém notamos que esse impacto se amplia em famílias que fundamentam sua vida econômica na lavoura, no trabalho com a terra para produção do alimento. Espaços naturais de matas, campos, rios, sempre fizeram parte da forma de organização do trabalho dos lavradores. Percebemos isso nos locais de pesquisa, como por em exemplo em Aiuruoca, especificamente, no Bairro da Pedra, a presença de um parque de conservação proibiu o uso dos campos de altitude para criação de gado. Essa prática centenária de criação de gado em campos naturais, era a base da economia local pois, além da venda do leite, também existiam pequenas unidades de fabricação de queijo, principalmente o parmesão. Hoje é comum ouvirmos na região que o leite acabou, só subsistindo uma pequena parcela da produção de leite, o que obriga as poucas famílias que continuaram com a fabricação do queijo parmesão, a buscarem leite de outros locais, o que encarece o queijo, aumenta o trabalho e o custo do artesão do queijo.

Citamos a seguir o diálogo ${ }^{5} \mathrm{com}$ um morador de Padre João Afonso em Itamarandiba que discorre sobre os locais de terras e suas utilidades para plantio:

\footnotetext{
${ }^{5} \mathrm{O}$ entrevistador é indicado com a letra $\mathrm{M}$, e o entrevistado com a letra $\mathrm{V}$.
} 
M- Para o agricultor familiar, ele considera aquela terra produtiva? Assim, aquele valezinho lá do Padre João Afonso, a maioria ali é terra produtiva?

V- Sim.

M- É terra escura, terra...

V- É, ela é uma terra escura, algumas partes avermelhadas e algumas partes na beira do rio, né? Que eles fala, as vazantes, tem uma terra mais amarelada, uma terra mais argilosa. Enquanto as partes mais altas, aquelas grotas, as terras são mais arenosa argilosas, sabe? Mas são produtivas. Aquelas grotas, aquelas baixadas, são muito produtivas. Os altos não. Os altos são mais produtivos assim, pra mandioca.

M- E como é que você divide a produção, vamos supor: no alto, mais mandioca, e nos outros, as outras culturas? Seriam em que região?

$\mathrm{V}$ - O arroz produz mais nas margens, né?

M- É aquele arroz que precisa de água né?

V- Não, ele não precisa de água. Ele precisa de um terreno úmido, que permaneça úmido. Mas ele não precisa da água mesmo não.

M-Por que tem um que precisa, né?

$\mathrm{V}$ - Isso! E o feijão e o milho produz bem nas encostas, né? A terra não pode ser muito úmida como a do arroz, mais nas encostas e nas baixadas, e já a mandioca ela produz melhor em um terreno mais alto. Aliás, ela produz em qualquer terreno, mas só que ela produz bem na terra alta, cê deixa ela nas terras altas e vai plantar as outras na terra baixa, né? É uma questão de aproveitar a terra.

M- Aproveitar a terra, né? E você acha que esse conhecimento a maioria dos agricultores familiares de lá tem?

V- Tem. Com certeza.

M- Mas esse conhecimento você acha que conseguiu passar pros filhos? Pra nova geração? Vamos supor: aqueles alunos ali da escola Padre João Afonso, tem esse conhecimento? Alguns eu até percebi que tem, né? Mas cê acha que a maioria tem? Essa percepção do uso do solo, onde eu planto isso, onde eu planto aquilo... Cê acha que eles ainda tem isso assim, ou não?

V- A maioria não. Assim, muitos ainda tem, principalmente os que ainda estão nessa prática com os pais, né? Acho que tem uma percepção bem maior, agora quem já não tá muito nessa prática, acho que já não tem muito essa percepção. Talvez assim, no geral é que tenha, né? Mas não assim, essa percepção de que mandioca produz bem na baixada e no alto, é pra aproveitar o alto, já que ela produz lá, planto ela lá, e deixo a baixada pra plantar o feijão e o milho, que produz bem aqui, e não produz bem lá. Talvez tenha uma percepção mais no geral, a percepção que produz tudo aqui na baixada.

A fala que acabamos de ler do morador de Padre João Afonso específica a percepção da natureza pela lógica do trabalho com a terra e como esta relação com a terra de trabalho se relaciona com a 'terra natureza', ou seja, há uma leitura prévia da terra em seus aspectos 'originais' e a relação desses aspectos para o tipo de cultivo do alimento. Compreendemos a percepção como uma forma de relação com o mundo. 
vivência corporal, de modo que a situação de nosso corpo e as condições de nosso corpo são tão importantes quanto a situação e as condições dos objetos percebidos. (CHAUÍ, 2000, p.154)

[...] a percepção envolve nossa vida social, isto é, os significados e os valores das coisas percebidas decorrem de nossa sociedade e do modo como nela as coisas e as pessoas recebem sentido, valor ou função. (CHAUÍ, 2000, p.157)

Assim a natureza é traduzida pela cultura. A relação com a natureza, no sentido de responder as necessidades das pessoas de uma dada comunidade, reflete um saber estruturado empiricamente, ou seja, na experiência do trabalho cotidiano; que, por sua vez se relaciona com uma visão religiosa do mundo, forjando assim uma lógica própria de se relacionar com natureza. Pois:

[...] para nós (sociedade humana) qualquer dimensão da natureza será sempre um ambiente percebido através de uma cultura, e também um 'lugar de viver' construído como uma dimensão da natureza tornada parte de um modo humano de vida. Isto é, uma dimensão de meio ambiente transformado e culturalmente socializado, para de alguma maneira fazer parte dos mundos sociais que construímos para viver e para conviver. Mundos de vida que criamos e aos quais atribuímos sentidos. Ideias e valores, preceitos e princípios compartidos e dados a nós mesmos, aos nossos outros e ao mundo onde partilhamos nossas vidas e destinos. (BRANDÃO, 2015, p.73)

\section{TRABALHO E NATUREZA}

A conversa se dá entre espaços sociais: na sombra de uma árvore, dentro da cozinha sentados no chão batido, ao lado da fogueira. Entre luzes tremulas, onde as sombras habitam, a palavra flui encontrando o ouvir. ${ }^{6}$

Philippe Descola em seu livro 'Outras naturezas, outras culturas' (2016) nos indica, pelo próprio título, que a conceitualização daquilo que chamamos de natureza, diz muito sobre a cultura que está a dizer sobre o mundo não humano, ou seja, a concepção da natureza, revela o mundo cultural criado por uma sociabilidade humana e seus valores.

Em conversas com lavradores do alto Vale do Jequitinhonha, percebe-se como os mesmos concebem o que é natural e o que não é. Primeiro existe um aspecto religioso: tudo na natureza foi Deus quem fez, sendo assim, na natureza uma coisa pode estar ligada a outra; enquanto uma flor nasce numa árvore, em outra nasce o fruto, enquanto uma é rasteira outra cresce muito. Mas tem uma coisa muito importante, nem tudo que parece natureza é natureza. Os lavradores não percebem as extensas plantações de eucalipto como natureza, como coisa que foi Deus quem fez. O que se destaca nessa visão é que em plantação de eucalipto só tem eucalipto, não existe a diversidade que Deus criou. É uma planta que só vive com ela mesma e isso não é natureza. Mas se fazemos uma comparação entre o olhar do lavrador com alguém que vive nos grandes centros urbanos, para este último os extensos monocultivos de eucalipto são natureza, pois são árvores, verdes

\footnotetext{
${ }^{6}$ Autor. Comunicação pessoal. 01 out. 2018.
} 
e nascidas no solo. Essa visão urbana do que seria natureza demonstra a condição humana de quem fala, uma condição que se caracteriza pelo afastamento do seu meio ambiente, pelo distanciamento entre a ação humana e sua produção e o mundo dito natural. Já para os lavradores, que vivem mais próximos do seu meio ambiente natural, a natureza é concebida de uma forma holística e complementar com a ação humana.

Bom. Eu acredito, no meu modo de pensar, eu acredito, que antigamente, era difícil a madeira pra construção de uma casa e tudo, aí até que o eucalipto trouxe algo de bom, mas eu acho que ele deu um desequilíbrio por causa que é muito. Tudo muito passa da conta, né? Então eu acredito que por ser muito grande a área acho que trouxe [desequilíbrio], nós [da comunidade Padre João Afonso] ainda não estamos sentindo não, mas estamos começando a sentir um desequilíbrio na natureza, porque é uma planta só, o eucalipto é uma planta só, ali não vegeta nada entre o eucalipto. Então tem aí uma área de trinta quilômetros, e nesses trinta quilômetros não encontra nada.

Só o eucalipto. $E$ as vezes passa um bicho ali, mas ele não acha nada de comer, porque na verdade, Deus criou o mato nativo, e ali é um lugar assim, que dá uma fruta num mês, um pau que dá fruta em outro mês, e por aí passa a ter alimentação 0 ano inteiro, né? A gente tá começando a sentir, e por aí vem que a natureza é completa, e a partir do momento que falta uma coisa começa a faltar as coisas, porque é uma coisa ligada com a outra, né? (Morador V.)

Cabe salientar que na percepção de natureza demonstrada na fala do morador, torna-se evidente o contraste que há com as práticas econômicas dos monocultivos de eucalipto. Na leitura realizada pelo lavrador destaca-se o fato dos mesmos não considerarem a natureza como um mero recurso, e também não concebem a plantação de uma árvore só como natureza. Para ele a natureza é um todo coordenado por uma diversidade de vidas que se organizam por uma contínua troca de alimentos entre os seres viventes. A natureza seria um espaço de vida, do contínuo da vida. A percepção vem do habitar.

No Vale do Jequitinhonha:

[...] o sítio do camponês como unidade produtiva consiste num sistema de composto por subunidades funcionais que correspondem a estratos de paisagem. Uma importante característica do sistema produtivo local é a complementariedade dessas subunidades ecológicas que compõem o sítio camponês. Nesse caso, o que temos são unidades intercambiáveis, mas interdependentes, posto que se sucedem no ciclo produtivo, fornecendo trabalho e alimento em períodos distintos. O caráter conexo, mas não substitutivo dessas unidades também se revela quando consideramos as diferenças relativas ao tipo de recursos que provem as famílias: o mantimento e a miudeza, produtos para a despesa e para o negócio. (OLIVEIRA; ZHOURI, 2012, p.201)

A forma de organização social do trabalho na comunidade camponesa tradicional é fundamentada na família e também no trabalho coletivo com outras 
famílias; a força de trabalho familiar ainda hoje se faz presente, já o trabalho coletivo (mutirão) ficou esporádico, este, quando acontece, envolve a comunidade em seu todo. Já a troca de dias (outra modalidade de organização de trabalho no mundo rural) representa um combinado entre uma ou mais famílias. A relação estabelecida na categoria de 'trabalho trocado' se dava devido ao fato de não terem relação direta com o dinheiro, enquanto forma de pagamento. O 'pagamento', se assim podemos dizer, se dava pela troca do trabalho. Esta forma de organização do trabalho solidificou uma lógica de ocupação do solo, forma de plantio, colheita, a 'limpa' das plantações, etc., que permeou a organização da família e as alianças de parentesco, constituídas pelos casamentos.

Esta forma de organização social do trabalho fundamentada pela troca, seja de trabalho, ou troca de bens como sementes e alimentos, criou no grupo uma moral coletiva, uma noção de pertencimento sociocultural dos membros do grupo, pois esta forma de organização social do trabalho permitiu ao grupo certa 'autonomia' socioeconômica e cultural em relação à sociedade envolvente, apesar dos laços de dependência como um corolário da ordem social estabelecida. Ou seja, o grupo, para se manter socialmente ativo com valores próprios, forjou modelos econômicos e culturais que permitiu uma resistência social e cultural que se mantém até os dias de hoje.

\begin{abstract}
Desse modo, o fluxo das atividades de trabalho e as alternâncias ecológicas sazonais se articulam produzindo condições de vida indissociáveis das relações que as pessoas mantêm com seu meio. Sublinhamos, pois, as práticas e os conhecimentos que compõem um sofisticado sistema de usos de recursos com um fino ajustamento entre capacidades ecológicas das áreas e o potencial de produção dos grupos domésticos. É nesse sentido que a organização dos espaços e da classificação do ambiente estão relacionados a fatores como: as qualidades do solo e sua adequação a determinados produtos, o calendário agrícola e as variações sazonais na pluviosidade, a disponibilidade da força de trabalho doméstica, além da capacidade de alocação dos produtos de necessidades correntes das famílias. (OLIVEIRA; ZHOURI, 2012, p.199)
\end{abstract}

Podemos, neste momento, nos apoiar em Mauss e sua noção de fato social total, que nos ajuda a compreender a vida social como um sistema de relações de trocas: entre a comunidade humana consigo mesma e, desta, para com a natureza.

\begin{abstract}
Nesses fenômenos sociais 'totais', como propomos chamá-los, exprimem-se, de uma só vez, as mais diversas instituições: religiosas, jurídicas e morais - estas sendo políticas e familiares ao mesmo tempo -; econômicas - estas supondo formas particulares da produção e do consumo, ou melhor, do fornecimento e da distribuição -; sem contar os fenômenos estéticos em que resultam esses fatos e os fenômenos morfológicos que essas instituições manifestam. (MAUSS, 2003, p.187)
\end{abstract}

Os agricultores familiares, os homens e mulheres lavradores da terra, percebem que o trabalho que desenvolvem é uma troca com a natureza, principalmente com a terra, além disso, indicam, indiretamente, que suas práticas de plantios 'alimentam a terra' e que recebem de volta o alimento, mediado pela ação 
de seu trabalho.

Mauss nos diz que as trocas não se limitam aos bens materiais mas as várias ações e objetos:

\begin{abstract}
Ademais, o que eles trocam não são exclusivamente bens e riquezas, bens móveis e imóveis, coisas úteis economicamente. São antes de tudo, amabilidades, banquetes, risos, serviços militares, mulheres, crianças, danças, festas, feiras, dos quais o mercado é apenas um dos momentos, e nos quais a circulação de bem mais permanente. (MAUSS, 2003, p.191)
\end{abstract}

Esta compreensão do trabalho, enquanto mediação da comunidade para com a natureza, cria um processo de valorização moral do mesmo, e, se nos tempos de antes, esta moral também se expressava nas práticas de ajuda mútua alicerçadas nas trocas de trabalho, hoje observamos nessas comunidades, os alimentos sendo 'presenteados' entre os moradores. Essas trocas, como diria Mauss,

[...] exprimem unicamente apenas um fato, um regime social, uma mentalidade definida: é que tudo, alimento, mulheres, filhos, bens, talismãs, solo, trabalho, serviços, ofícios sacerdotais e funções, é matéria de transmissão e de prestação de contas. Tudo vai e vem como se houvesse troca constante de uma matéria espiritual que compreendesse coisas e homens, entre clãs e os indivíduos, repartidos entre as funções, os sexos e gerações. (MAUSS, 2003, p.203)

Isso nos leva a compreender a vida social como um sistema de relações. A questão da troca realizada entre o agricultor e a terra no momento em que cultivam permite uma percepção do tempo/espaço camponês:

[..] a troca restaura simbolicamente um tempo mitificado e procura trazer para dentro desse tempo os "tempos modernos", o "tempo de transformação", expressão local de uma "grande transformação" que aqueles protagonistas tentam domesticar. A troca entre os homens é a continuidade das trocas com a natureza, pois é a troca de alimentos (que resultam da troca com a terra) e de trabalho (que constrói a terra e produz alimentos). O espaço camponês é, portanto, um espaço moral. (WOORTMANN, 1990, p.36)

Quando nos referimos ao uso tradicional da terra por parte do lavrador/camponês, devemos perceber que o mesmo, com o seu trabalho, constitui os espaços sociais e os estritamente 'naturais', apesar de haver uma relação constante, mediada pelo social, entre a comunidade e a natureza envolvente, pois o processo de trabalho se assessora em elementos naturais como a chuva, o sol e as nascentes. A comunidade interpreta, através da vegetação nativa, a qualidade da terra e para que tipo de plantio serve. Por exemplo, a presença de angicos e aroeiras juntos indica terra boa, segundo a percepção/empírica camponesa.

Essa inter-relação entre a construção dos espaços sociais e a sua relação com os espaços naturais mediados pelo trabalho, perpassa uma lógica pautada na oposição binária expressa na ideia do seco/úmido, quente/frio, terra fraca/terra forte, lua boa/lua ruim, escuro/claro, e assim por diante. 
A inter-relação (citada acima) demonstra a compreensão baseada numa lógica originada por uma experiência empírica de vários anos, passada de família para família e que pauta o trabalho do lavrador/camponês com a terra. E também nos leva a compreender com maior profundidade as práticas de plantio da comunidade, evitando, assim, de cairmos num reducionismo alicerçado num jogo de comparações entre as técnicas modernas de agricultura voltada exclusivamente para a produção de mercado, em detrimento de uma prática agrícola familiar voltada para o consumo próprio, o que, inevitavelmente, nos levaria a uma leitura preconceituosa dessa prática de cultivo. Assim, à primeira vista, o trabalho desenvolvido pelo lavrador/camponês poderia ser visto como uma prática primitiva, arcaica ou, na melhor das opções, simples, e teria como característica a ausência de técnicas (maquinário, insumo químico, etc.). Antes de ser uma técnica que apresenta ausência de maquinários, a técnica do trabalho agrícola do lavrador/camponês é antes de tudo uma técnica complexa que envolve conhecimento empírico, prático e conhecimentos teóricos estruturados por um imaginário social que envolve sua visão de mundo. Lévi-Strauss (1989) denomina isso de ciência do concreto.

Esta visão de mundo coloca a necessária mediação do trabalho humano como uma expressão religiosa do mundo, da vida como um todo. Deste modo o trabalho do lavrador/camponês na roça não envolve apenas a esfera econômica ou alimentar da comunidade, envolve a sociabilidade do grupo como um todo, tocando nas esferas do religioso, das práticas culturais e costumes, como na estrutura familiar que é a base da divisão social do trabalho. Assim o trabalho na terra de cultivo envolve: a estrutura familiar; a moral camponesa, a identidade-étnica; o conhecimento empírico da terra e dos recursos naturais; o conhecimento religioso que auxilia no plantio como as orações contra as pragas, simpatias para o cultivo crescer, orações para chover etc.; a concepção social da terra de cultivo e do território necessário para a constituição social da vida do grupo/comunidade; as expressões culturais, como danças, festas, ritos religiosos que ocorrem antes, durante e depois do trabalho coletivo ou familiar. Cantos entoados durante e depois da lida na roça, acompanhados por uma culinária própria; festa, encontro social, namoros, casamentos...; percepção cosmológica da lua, do vento, etc. Esse conjunto de elementos demonstra a interrelação entre a materialidade (natureza) sua parte imaginária (representação social) para a organização do modo de vida do agricultor familiar no alto Vale do Jequitinhonha e no Bairro da Pedra, Sul de Minas Gerais.

\begin{abstract}
São antes de tudo as diversas maneiras como os homens imaginam suas relações entre eles e com aquilo que chamamos de natureza que distinguem as sociedades, assim como as épocas durante as quais algumas delas continuam a existir. Mas o imaginário não pode se transformar em social, fabricar "sociedade", existindo apenas 'idealmente'. Precisa materializar-se em relações concretas que tomam forma de conteúdo nas instituições e, claro, nos símbolos que as representam e fazem com que correspondam entre si, que se comuniquem. 'Materializando-se' em relações sociais, o imaginário torna-se parte da realidade social. (GODELIER, 2001, p.46)
\end{abstract}

Compreendemos a representação social como a 'materialização' de um conjunto de relações sociais que "tomam forma de conteúdo nos símbolos que as representam" como dito pelo autor acima citado. Assim, o conto, é a 'materialização' 
de relações sociais entre o ser humano consigo mesmo e com aquilo que chamamos de natureza, sendo portanto uma representação social.

\title{
3. ESPIRITUALIDADE E TRABALHO
}

A religião popular não é mais identificada como costume religioso exótico, ela é agora apreendida como expressão de resistência. A religiosidade popular é um protesto das pessoas oprimidas, das classes dominadas, que se organizam em um sistema de crenças e práticas, em um deus ou outra divindade, ocorrendo uma auto produção religiosa, na qual os sinais e os símbolos do sagrado são recriados para poderem ser de novo amados e acreditados. O povo, como participante produz e reproduz um campo religioso no qual os símbolos e lutas seculares são recobertos com os nomes do sagrado. Não existe um conhecimento sistematizado e, sim, um conjunto de mitos e práticas do sagrado que se constitui em um saber oral, um repertório de crenças e ritos recriados na memória coletiva popular. (ROSENDAHL, 2002, p.73)

Desde muito tempo os teóricos sobre o comportamento religioso do brasileiro constataram uma pluralidade católica brasileira.

\begin{abstract}
Pode-se, porém, afirmar que pelo menos dois tipos de catolicismo coexistiram sempre no país: o catolicismo oficial e um catolicismo popular. Esta dualidade é antiga: "Já no período colonial, escreve Roger Batisde, encontramos dois catolicismos diferentes e muitas vezes em oposição: o catolicismo doméstico dos primeiros colonos, dos chefes de família, e o catolicismo mais romano, mais universalista, das ordens religiosas e principalmente dos jesuítas". (QUEIROZ, 1973, p.72)
\end{abstract}

A relação entre a terra e o lavrador (fundamentada no trabalho nas roças, criações de animais e coletas), demonstra uma particularidade no modo de ser da população rural no Vale do Jequitinhonha e que permeia comportamentos e valores dessas sociedades. No trabalho com a terra esta é sentida como um ser com vida própria, que sente cansaço, que precisa ser alimentada, que precisa ser conhecida. Esses saberes e relações são importantes para a realização do plantio e da colheita, e como são saberes que produzem alimentos fundamentais para a reprodução cultural e física da comunidade, são saberes que são vivenciados pela via do religioso, do que Deus manda e do comportamento ético entre o trabalhador e o seu meio de trabalho.

As pequenas comunidades que habitam o Vale do Jequitinhonha, assim como o Bairro da Pedra no Sul de Minas, formam uma rede de solidariedade que possibilita maneiras de se reproduzirem enquanto grupo social. Essa rede de solidariedade fundamentada pela reciprocidade entre seus membros, significa que não pode haver só quem recebe ou só quem dá, pois dar significa receber e vice versa. Assim, nessas comunidades, a troca como fundamento da reciprocidade é um traço preponderante na organização do trabalho e na ocupação familiar e coletiva da terra. A reciprocidade, enquanto postura ética na relação com o outro, seja esse outro humano, ou a natureza, se relaciona com a religiosidade do grupo. Práticas religiosas justificam num nível sobrenatural os saberes e fazeres tradicionais de cultivo e organização das atividades laborais na produção do alimento, na sua 
colheita e na sua divisão entre os membros da comunidade. "Para um homem religioso, a natureza não é exclusivamente natural, está sempre carregada de uma valor sagrado" (ROSENDAHL, 2002, p.64).

Como a espiritualidade é vivenciada no meio rural brasileiro? Muitas vezes pensamos a questão religiosa a partir da noção de religião institucionalizada, como por exemplo o catolicismo, e a partir daí procuramos acrescentar predicados a expressão catolicismo: rústico, popular, sincrético, rural.

Porém pensamos que a questão seria mais de espiritualidade do que religião, a espiritualidade aqui é pensada como o valor dado por comunidades à vida e ao conviver, habitar no mundo. O sentido de está vivo transcende a materialidade, a vida não é um momento, mais uma eternidade. Assim quando observamos formas locais de espiritualidades, tocamos nos mecanismos sociais e culturais que organizam o modo de ser e pensar e estar no mundo.

Nas distâncias de estradas de terra e de asfalto encontram-se localidades que possuem comunidades humanas que vivem seu modo de ser, que possuem valores, costumes e hábitos que diferem da população urbana. Comunidades que buscam organizar e manter sua visão de mundo, não como uma oposição ao mundo urbano, mas como uma outra maneira de ser e viver a condição humana nesse mundo, com semelhanças e diferenças, assim se dá no aspecto da espiritualidade das comunidades rurais aqui envolvidas.

A maneira como as comunidades rurais organizam sua vida religiosa demonstra as respostas sociais dadas as necessidades culturais, como a espiritualidade. A constituição da vida religiosa, em nossos estudos das comunidades rurais, revela em primeiro lugar uma atitude autônoma da comunidade para a constituição de espaços religiosos como igrejas e capelas. Em geral a construção das igrejas e capelas se dava pelo mutirão, pela associação dos moradores: doação do terreno, doação de materiais e de trabalho coletivo e alimentação coletiva.

Outro aspecto é a presença e não presença de padres nessas igrejas distantes dos espaços urbanos. Essa presença inconstante provoca mecanismos próprios de reflexões sobre as palavras da bíblia, dos ensinamentos da palavra de Deus. Além desses dois aspectos voltados para uma leitura da igreja enquanto instituição no meio rural, se faz importante focar na visão mítica de mundo que essas populações mantém e que são expressas em contos e causos ou práticas de ritos que entrecruzam saberes religiosos, provoca assim uma manifestação de espiritualidade que demonstra mais uma prática espiritual, do que uma prática de religião.

O espaço sagrado,

[...] um campo de forças e de valores que eleva o homem religioso acima de si mesmo, que o transporta para um meio distinto daquele do qual transcorre sua existência. É por meio dos símbolos, dos mitos e dos ritos que o sagrado exerce sua função de mediação entre o homem e a divindade. [...] A experiência do espaço sagrado se opõe à experiência do espaço profano para 0 homem religioso. O primeiro tem um valor existencial para ele: é seu referencial. A revelação de um espaço sagrado permite que se obtenha um "ponto fixo", ponto de toda orientação inicial, o "centro do mundo". (ROSENDAHL, 2002, p.30-31)

Neste sentido compreendemos que os contos e causos refletem esse espaço religioso, sagrado, assim como o profano. Para tanto apresentaremos a 
seguir a síntese analítica de alguns contos coletados, no intuído de demonstrar as redes que se articulam, o falar e o ouvir em comunidades de lavradores/camponeses.

\section{Vale da morte (Aiuruoca)}

Caçar peixe no rio. Trocava o peixe caçado na venda por mantimento. Trocar o trabalho na roça por alimento. Mas um dia não conseguiu vender peixe, trocar por mantimento. Dar a primeira coisa que encontrar no caminho. Dar o quê não se tem, e não conhece. Dar o quê não se tem para ganhar muito peixe. Dar o cachorrinho. A fala, a palavra dou, como comprometimento. Depois que confirmou o trato encheu de peixe seu barco. Não encontrou seu cachorrinho, mas sim seu filho. O narrador dizendo que ouviu o que o menino disse. $O$ menino cresceu e ia se defender do inferno. Armas de fogo, pára numa casa de um homem cheio de armas. A porteira como entrada do inferno, ao meio dia ela pára de bater, aí entra. Na floresta/campo: conversa com o capeta no inferno e a perda de um dedo. O menino muito arteiro. O homem que devia 190 mortes para se salvar tem que comprar uma navalha, e se cortar em 190 pedaços, dá um pedaço para cada pássaro preto que representa uma alma de cada pessoa que foi morta pelo homem. Só no último pedaço a alma sobe para o céu e a caveira desce. Tudo isso em cima de uma árvore. Cada pedaço de seu corpo era alimento para o pássaro da alma. A troca entre corpo e alma, a terra que engole o céu que puxa (eixo mundo representado pela árvore). A troca entre peixe e alimento, a troca entre a criança e o cachorrinho. $O$ conto se refere a uma ética da troca, a troca do trabalho por mantimento, a troca do filho pelo mantimento, a troca da carne com a alma.

\section{Papior (Padre João Afonso)}

Ir caçar na semana santa não pode, pois não se come carne, não varre a casa, não penteia o cabelo, é sexta feira santa. Com Deus não se brinca. Mas o marido foi para o mato. Viu um pássaro preto e grande. O pássaro fala ao cantar. - Não me pegue agora deixe eu falar primeiro. - Não me apronte agora deixa eu falar primeiro. A ave mesmo morta falava: - Papior, a ave sempre repete essa palavra: - Não me come agora, deixa eu falar primeiro, agora pode comer, Papior. - Não me cague agora, deixa eu falar primeiro disse o pássaro, antes da barriga do homem (marido) estourar.

\section{A voz do cupim (São Gonçalo do Rio das Pedras)}

A voz: - Você quer no presente ou no futuro? A mulher (do fazendeiro) diz para responder no presente, pois agora eles tem mais saúde. Logo depois do fazendeiro falar "sim" um fogo queimou tudo que era seu, só se salvou a mulher, filhos e uma trouxa de roupa e dinheiro. Saiu pelo mundo. Vai andando a mulher com a trouxa na cabeça. Rio largo que não dava pé. Rio, árvore, uma galha da árvore que pendia na parte mais funda do rio. Uma águia pousa no galho da árvore depois que pegou a trouxa de roupa da mulher. E foi tirando peça por 
peça. Um canoeiro fazia a travessia para o outro lado do rio. Quando atravessavam no meio do rio a canoa virou e separou a família, as águas que separam. O homem se salvou e foi trabalhando, trabalhando... na cidade onde 'ranchou'. O homem trabalhou para um rei, como ele era bom trabalhador o rei doou sua coroa para ele. A mulher em outra cidade trabalhando, trabalhando... Num domingo, conversando com as amigas na rua. Os meninos, rapazes, assentaram praça. Depois do encontro do marido com a mulher e os dois filhos, foi uma festa a semana inteira.

\title{
4. SOBRE OS CONTOS
}

Esses contos e a forma de narrar perpassam o ar do tempo, carregado de experiência, daquela velha experiência do viver, que nos faz falar e ouvir. No desejo de aprender, aprendemos como escutar, pois a fala falada, a voz, precisa do seu meio social, precisa e regra as relações sociais.

Quando ouvimos os narradores, não ouvimos apenas sua voz, mas o seu tempo de vida na forma de experiências narradas, as palavras ditas são carregadas de ensino, de conselhos forjados na experiência do viver, carregadas de uma memória coletiva, de hábitos e costumes que criam visões de mundo.

A experiência é um tema fundamental para se pensar o mundo contemporâneo, como podemos pensar num existir sem experiência, como suportar o mundo sem a experiência e o valorar da mesma, Agambem (2005) nos lembra baseado em Walter Benjamim em 1933 que:

\begin{abstract}
Todo discurso sobre a experiência deve partir atualmente da constatação de que ela não é mais algo que ainda nos seja dado fazer. Pois, assim como foi privado da sua biografia, o homem contemporâneo foi expropriado de sua experiência: aliás, a incapacidade de fazer e transmitir experiências talvez seja um dos poucos dados certos de que disponha sobre si mesmo. Benjamin, que já em 1933 havia diagnosticado com precisão esta <pobreza de experiência> da época moderna, indicava suas causas na catástrofe da guerra mundial... (AGAMBEM, 2005, p. 21).
\end{abstract}

Neste sentido fica evidenciado que os contos, ao serem narrados, permitem trocas de experiências simbólicas do viver no mundo e das relações humanas nesse viver o mundo, experiência que se faz carente no mundo contemporâneo e urbano, mas que ainda perpassa o viver de comunidades rurais que mantém uma relação íntima com a terra e as outras formas de vida que compõem o espaço socioambiental dessas comunidades.

Nos contos encontramos relatos que buscam enfatizar a relação: trabalho, natureza e religiosidade. Em um conto temos a figura do pe(s)cador (aquele que caça 0 peixe segundo a narradora). Com o peixe o pescador podia acessar mantimentos que não produzia, ele ia para feiras ou mercados e vendia ou trocava seus peixes, para com isso conseguir outros mantimentos, mas houve um dia que ele não conseguiu peixe, nessa situação, uma voz, denominada pela narradora como a voz do 'coisa ruim', propôs uma troca: o pescador deveria dar a primeira coisa que encontrasse em seu caminho e, em troca, seu barco ficaria cheio de peixes. O pescador lembrou que sempre quando voltava a primeira coisa que encontrava era o seu cachorrinho, sendo assim aceitou fazer a troca com o 'coisa 
ruim', no momento que, pela sua fala aceita o acordo, seu barco se enche de peixes. Porém no retorno para casa encontra primeiro seu filho.

Mas o que nos chama a atenção no conto é que essa parte da narração é um ensejo para a parte mais importante do conto, que é a troca entre o matador de gente e as almas das pessoas que ele matou. O matador se salva do inferno pois sobe numa árvore bem alta, onde encontra 190 pássaros pretos que representam as 190 almas que o matador matou. O homem foi tirando com uma navalha, pedaços de seu corpo que dava para as almas, enquanto passarinhos, até chegar a ultima parte de seu corpo, assim morrendo, a caveira do caçador desceu para debaixo da terra e sua alma subiu para o céu.

A troca se apresenta como o elemento chave dessa narração: a troca entre o pescador e o 'coisa ruim', a troca dos peixes por outros mantimentos, a troca entre o matador e as almas. Outro elemento chave é o trabalho como mediador da narração, o trabalho como a resposta necessária para sobreviver. Também elemento importante, a mata e a presença da árvore como um eixo mundi.

\begin{abstract}
Uma árvore impõe-se à consciência religiosa pela sua própria substância e pela sua forma, mas esta substância e esta forma devem o seu valor ao fato de que se impuseram à consciência religiosa, de que foram "escolhidas", quer dizer, se "revelaram". Nem a fenomenologia da religião nem a história das religiões poderiam superar a constatação dessa coexistência da natureza e do símbolo que a intuição do sagrado vem valorizar. (ELÍADE, 1993, p.216).
\end{abstract}

Segundo este mesmo autor a árvore simboliza um eixo-mundi pelas suas característica: renasce e morre (queda de folhas e renovação das folhas); tem a posição vertical tocando o fundo da terra com suas raízes (profundo o interno) e 'tocando' o céu com suas folhas e galhos (o alto, o externo). No conto a árvore tem essa função simbólica, pois o homem que devia 190 mortes subiu na árvore para fazer a reciprocidade do seu corpo com as almas dos corpos que ele matou, sua alma sobe e sua caveira desce recriando assim o eixo-mundi representado simbolicamente pela árvore.

No conto 'Papior', novamente observamos o trabalho, o homem caçador, mas que não podia caçar na semana santa, principalmente na sexta-feira santa, mas o homem quebra essa regra, esse tabu, e vai para a mata caçar. Encontra com um pássaro que nunca tinha visto, um pássaro que fala: antes de ser caçado, antes de ser preparado, antes de ser cozido e antes de ser comido. O homem caçador ao comer o pássaro estranho morre, a sua barriga explode. Observamos a presença dos pássaros, a presença da árvore, da floresta. Nos dois contos há uma quebra de regra, pensada no conto como pecado, mas que podemos pensar como quebra de tabus. No conto 'a voz que vem do cupim', nos encontramos novamente com uma voz oculta, misteriosa, e também com o trabalho no campo, com árvores, rios, e pássaros. A noção temporal presente e futuro (destino); perder tudo (materialidade), se separar da família (sofrimento), recuperar tudo pelo trabalho, festejar, se transformar em rei e rainha.

Todos esses contos quando ouvidos, traduzem um deixar viver, experienciar a vida e suas circunstâncias. Valores sociais se destacam: o trabalho, religião, visão mítica do mundo, experienciar com o corpo, troca social entre o humano e os seres da natureza, a voz.

A águia, a ave que faz o último despojar dos bens do casal (no conto 'Voz do cupim'), em cima de um galho alto, que alcançava o meio do rio (a águia), depois 
que pegou a trouxa da mulher, começou a jogar, roupas e a carteira de dinheiro, para dentro do rio. Uma ave, a árvore e o rio.

O ser humano e a natureza. Uma velha questão, porém se uma questão se mantém, é porque ainda precisa de respostas, neste sentido em relação as velhas perguntas temos que levar em consideração as velhas respostas, não para nelas estancar, mas para delas caminhar.

\section{CONSIDERAÇÕES FINAIS}

Os contos e as narrações apresentados nos demonstram uma visão de natureza que ainda traz consigo o encantamento do mundo, afastando-se assim de uma percepção instrumental da natureza. Nos contos os seres da natureza possuem voz, falam, participam como sujeitos da história que envolve humanos e não humanos.

O imaginário social expresso em contos e narrações nos permite uma observação mais complexa do real social vivido, assim o imaginário se relaciona com a memória. A memória, como um fenômeno social, se constrói dentro e no social. Pois a ação do grupo social determina a reconstrução das lembranças, tornando a memória um fenômeno social. Os contos coletados apresentam substratos didáticos, aprendizados estéticos e morais, pois representam, de forma literária, condutas que as pessoas deveriam ter ou respeitar para uma melhor relação com o mundo social e natural envolvente, assim como entre as pessoas, no seu cotidiano. Pois são 'recados' sociais validados pelos mais velhos, pela experiência da vida. Assim os contos são didáticos por expressarem sentidos éticos, econômicos, religiosos e comportamentais.

Robert Darnton em seu livro 'O grande massacre de gatos: e outros episódios da história cultural francesa' (2011) analisa: "as maneiras de pensar (...) não apenas o que as pessoas pensavam, mas como pensavam - como interpretavam o mundo, conferiam-Ihe significados e Ihe infundiam emoção." (p. 13). $\mathrm{O}$ autor indica como a vida comum exigia uma estratégia: "pensam com coisas, ou com qualquer material que sua cultura lhes ponha à disposição, como histórias ou cerimônias." (p.14)

Os contos eram narrados, o autor nos diz, em torno de lareiras, nas cabanas dos camponeses, durante as longas noites de inverno. "[...] as histórias pertencem sempre a um fundo de cultura popular, que os camponeses foram acumulando através dos séculos, com perdas notavelmente pequenas." ( $p .32$ ) O narrador (cantor) cria seu texto ao narrá-lo fazendo novos caminhos através de velhos temas (a diversidade na forma de narrar uma mesma história), mas apesar dessa diversidade da forma de narrar e acrescentar outros elementos "as variações de detalhes, nos contos populares russos, permanecem subordinadas a estruturas estáveis" (p.34) as tradições orais têm um enorme poder de resistência. Nesse sentido Darnton nos afirma que:

[...] as tradições orais parecem ser tenazes e altamente duráveis quase em toda parte, entre os povos sem escrita. Também não se desmantelam com sua primeira exposição à palavra impressa. Apesar da afirmação de Jack Goody, de que uma linha de alfabetização corta toda a história, dividindo as culturas orais das "escritas", ou "impressas", parece que a narrativa tradicional de contos pode florescer muito tempo depois do começo da alfabetização. [...] não há nada extravagante na ideia de que os narradores camponeses no fim do século XIX, na França, contavam histórias um ao outro de 
maneira bastante parecida com a dos seus ancestrais, de um século antes, ou mais. (DARNTON, 2011, p.35)

Assim o conto revela uma leitura humana do mundo envolvente natureza/social. O conto pode ser pensado como um domínio 'conexo' do mito, segundo Pierre Lévêque (2005), o conto seria uma forma laicizada do mito. "Um domínio anexo deveria ser mais explorado do que é até agora: o do conto, forma laicizada do mito. Um exemplo bem estudado mostra tudo o que se pode daí extrair, o conto dos "objetos mágicos" [...]" (LÉVÊQUE, 2005, p.22).

Deste modo buscamos a formulação de ações que visibilizem e apoiem 'mestres/as' do lugar, ou seja, o/a sábio/a, o/a narrador/a, o/a memorialista, que existem muitas vezes 'invisíveis'. Assim constituir ações práticas e reflexivas no que se refere a questão de como apoiar moradores de comunidades rurais enquanto narradores, poetas, historiadores, que contam a história local, do lugar onde moram, ou seja, os guardiães da memória do lugar. Para tanto coletamos, sintetizamos narrações ou estudos sobre o local, formulados por moradores, desta forma contribuindo com o processo de auto valoração das comunidades rurais, ao compreenderem o valor e o sentido de seu lugar e de sua história.

\section{AGRADECIMENTOS}

Fundação de Amparo à Pesquisa do Estado de Minas Gerais (FAPEMIG APQ 002797-14) e Fundação Diamantinense de Apoio ao Ensino, Pesquisa e Extensão (FUNDAEPE). Pró-reitoria de Pesquisa e Pós-Graduação (PRPPG/UFVJM) e PróReitoria de Extensão e Cultura (PROEXC/UFVJM). Comitê de Ética em Pesquisa (CEP/UFVJM), parecer n. 1.623.266/2016.

\section{REFERÊNCIAS}

AGAMBEM, G. Infância e história: destruição da experiência e origem da história. Belo Horizonte: Editora UFMG, 2005.

BARROS, M. M. Memória e família. In: Estudos históricos III - Memória. São Paulo: Vértice, 1989.

BRANDÃO, C. R. Nós os humanos: do mundo à vida, da vida à cultura. São Paulo: Cortez, 2015.

BRASIL. Conselho Nacional de Saúde. Resolução 466/2012. Trata de pesquisas em seres humanos e atualiza a resolução $\mathbf{n}$. 196. Diário Oficial da União, 12 dez. 2012.

CHAUÍ, M. Convite a filosofia. São Paulo: Ática, 2000.

DARNTON, R. O grande massacre de gatos e outros episódios da história cultural francesa. São Paulo: Editora Graal, 2011.

DESCOLA, P. Outras naturezas, outras culturas. Coleção Fábula. São Paulo: Editora 34, 2016. 64p.

GODELIER, M. O enigma do dom. Rio de Janeiro: Civilização Brasileira, 2001. 
HALBWACHS, M. A memória coletiva. São Paulo: Centauro, 2006.

JOLLES, A. Formas simples: Legenda, saga, mito, adivinha, ditado, caso, memorável, conto, chiste. Trad. Álvaro Cabral. São Paulo: Cultrix, 1976.

LÉVÊQUE, P. Para uma análise comparativa de ideologias religiosas: Religiões africanas e religião grega. In: Mitos e civilizações. CARVALHO, S.M.S (org.). São Paulo: Terceira Margem, 2005

LÉVI-STRAUSS, C. Pensamento selvagem. Campinas: Papirus, 1989.

MAUSS, Marcel. Sociologia e antropologia. São Paulo: Cosac \& Naify, 2003.

OLIVEIRA, R.; ZHOURI, A. Experiências locais e olhares globais: Desafios para os moradores do Vale do Jequitinhonha (MG) no campo ambiental. In: Cultura, percepção e ambiente: Diálogos com Tim Ingold. Orgs.: STEIL, C. A.; CARVALHO, I. C. M. São Paulo: Editora Terceiro Nome, 2012 (Coleção Antropologia Hoje).

QUEIROZ, M. I. P. O campesinato brasileiro: ensaios sobre civilização e grupos rústicos no Brasil. São Paulo: EDUSP, 1973.

ROSENDAHL, Z. Espaço e religião: uma abordagem geográfica. Rio de Janeiro: UERJ/NEPEC, 2002.

TAUNAY, A. E. Relatos sertanistas. Belo Horizonte: Itatiaia, 1981.

VASCONCELOS, D. História antiga das Minas Gerais. Belo Horizonte: Itatiaia, 1974.

WOORTMANN, K. Com parente não se neguceia: o campesinato como ordem moral. Anuário Antropológico. Rio de Janeiro: Tempo Brasileiro, 1990. 